\title{
Mechanical Characterization Using Optical Fiber Sensors of Polyester Polymer Concrete Made with Recycled Aggregates
}

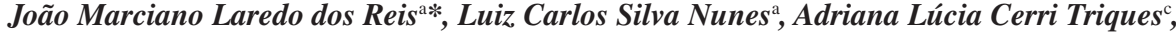 \\ Luiz Carlos Guedes Valente ${ }^{\mathrm{b}}$, Arthur Martins Barbosa Bragaa ${ }^{\mathrm{c}}$ \\ a Programa de Pós-Graduação em Engenharia Mecânica, \\ Laboratório de Mecânica Teórica e Aplicada - LMTA, Universidade Federal Fluminense - UFF, \\ Rua Passo da Pátria, 156, Niterói - RJ, Brazil \\ ${ }^{\mathrm{b}}$ Gavea Sensors, Fonseca Teles, 13, 20940-200 São Cristóvão - RJ, Brazil \\ 'Departamento de Engenharia Mecânica, Pontifícia Universidade Católica-PUC-Rio, \\ Rua Marquês de São Vicente, 225, 22453-900 Rio de Janeiro - RJ, Brazil
}

Received: September 2, 2008; Revised: May 26, 2009

\begin{abstract}
The sustainable management of solid wastes encourages metallurgic and metal-mechanic industries to look for safety applications for their wastes, thereby attenuating the environmental impact or lowering the costs. The study herein proposes strain monitoring the recycling of foundry sand with organic pollutants, as inert, in the manufacturing process of polymer concrete using optical fiber sensors. This work also analyzes the compressive strength of polyester polymer concrete made with foundry waste, i.e., recycled foundry sand and polyester polymer concrete made with fresh sand. The foundry sands are contaminated with Sodium Silicate from the mould-making process. Polymer Concrete (PC) is a composite material in which the binder consists entirely of a synthetic organic polymer. Optical fiber sensors present a great deal of potential in monitoring the structural health condition of materials. Experimental results show that the use of the embedded FBG sensor can accurately measure strain, providing information to the operator that the structure is subjected to failure. Multiplexed FBG strain sensors enable measuring strain in different locations by occupying only one tiny optical fiber.
\end{abstract}

Keywords: polymer, optical fibers, fiber reinforcement, recycling

\section{Introduction}

Polymer Concrete has been widely used to produce building cladding since the middle of the last century ${ }^{1}$. In recent years, the construction industry has progressed considerably with technical innovations, and the research and development of high-performance and multifunctional construction materials have been actively pursued to cope with the innovations. In particular, this trend is perceived in the new frontiers of the construction industry, i.e., super high-rise buildings, very deep underground space, ocean, and lunar base developments in advanced countries. The current development of construction materials should be ecologically safe and energy-saving from the viewpoint of global environment protection, apart from conventional development. A worldwide interest in concrete - polymer composites has become stronger ${ }^{2}$.

Polymer Concrete is a concrete-like composite, in which a resin binder, in this case polyester resin, substitutes the cement binder. The composition of PC is determined by its applications, and is used very efficiently in precast components such as manholes, pipes and chemical vessel, it also has important applications in concrete repair and anti-corrosion protection, including industrial flooring ${ }^{3,4}$.

Polymer concrete exhibits brittle failure behavior and it is therefore important to improve its post-peak stress-strain behavior ${ }^{5}$.

Fiber Bragg grating (FBG) sensors have generated much interest in recent years. They have proven to be reliable sensors to measure various physical, chemical and biological parameters ${ }^{6-8}$. The advan- tages of optic fiber sensing are well known, such as low weight, small dimension, long transmission distance, EMI immunity, etc... In addition, for FBG based sensors, there is the ease with which these sensors multiplex ${ }^{8}$.

Bragg grating depends on the effective index of core refraction and the periodicity of the grating. The effective refraction index, as well as the periodic spacing between the grating planes, will be affected by changes in strain and temperature. The refractive index itself is temperature dependent. The relative change in Bragg wavelength due to strain and temperature can be expressed by ${ }^{8}$.

$$
\frac{\Delta \lambda_{b}}{\lambda_{b}}=\alpha \Delta T+\beta \varepsilon
$$

where $\alpha=9 \times 10^{-6}{ }^{0} C^{-1}$ is the thermal coefficient and $\beta=0.78$ is the strain-optic constant associate with the temperature change $\Delta T$ and the applied strain $\varepsilon$, respectively.

Fiber Bragg grating has been employed in a variety of engineering applications involving internal strain measurements in composite plates monitoring and in-service structure control, damage detection $^{9-12}$. When the FBG is embedded in composite material all mechanical forces in the material are transmitted to FBG.

Different measurement techniques can be employed to determine strain and temperature variation associated to induced modification in the reflected spectrum of Bragg grating ${ }^{6-14}$. Frequently, the measure 
is taken with commercially available optical spectrum analyzers (OSA).

\section{Materials Used}

Sand is used in two different ways in metalcasting: as molding material, which forms the external shape of the cast part, and as cores, which form internal void spaces in products such as engine blocks. Since sand grains do not naturally adhere to each other, binders must be introduced to cause the sand to stick together and hold its shape during the introduction of the molten metal into the mold and the cooling of the casting.

The ecological advantages of molding sand with Sodium-Silicate as a binder are well known. On the other hand, the segment of the market that uses synthetic resin as a binder points to three principal disadvantages of this material: low primary resistance, unsatisfactory behavior of collapsing and difficult regeneration by dry and mechanical processes. Theses disadvantages are justified by the presence of

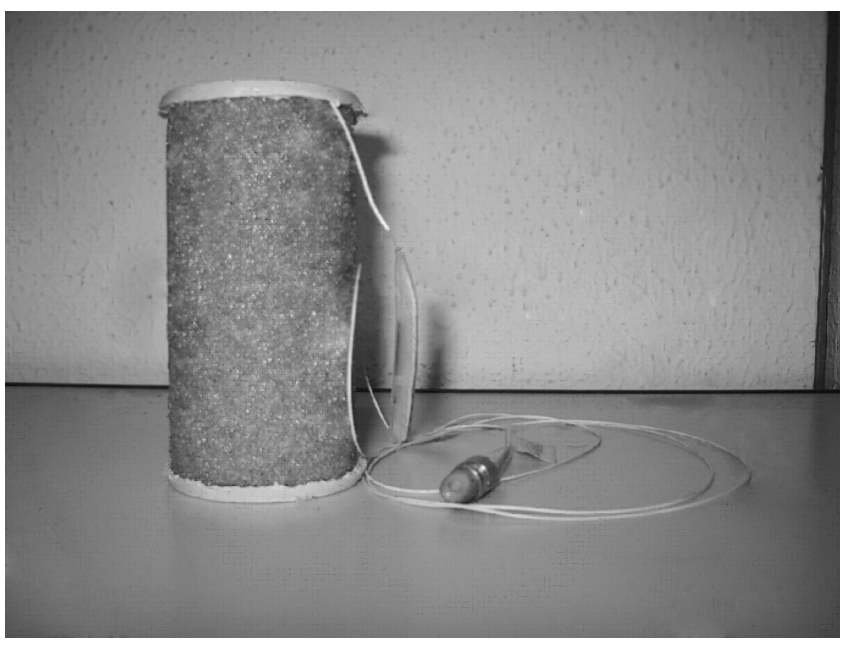

Figure 1. Specimen made with fresh sand.

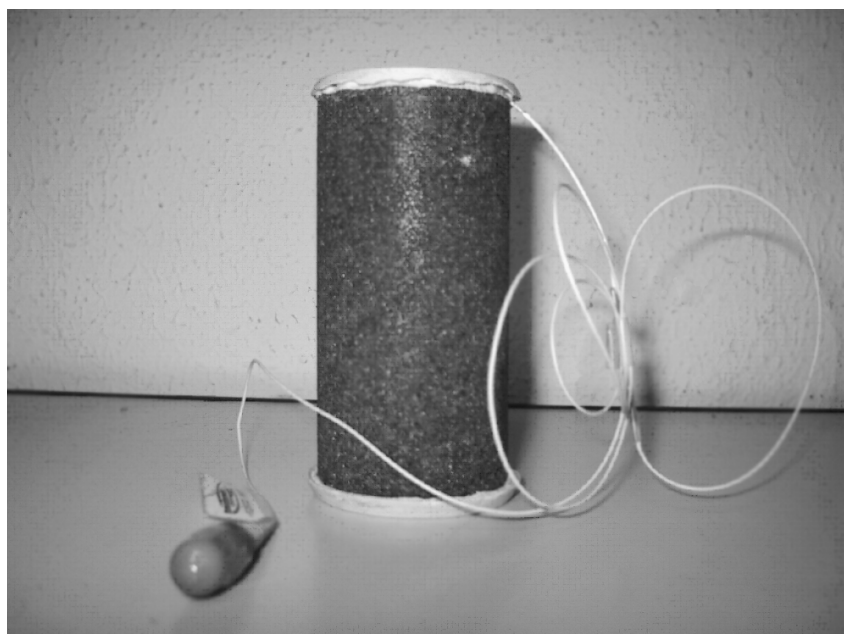

Figure 2. Specimen made with recycled sand.
Sodium ions and to the formation of a glass phase of chemically aggressive $\mathrm{Na}_{2} \mathrm{O}-\mathrm{SiO}_{2}$, obtained after the application of an electrical charge in the molding sand.

An alternative to raising the primary resistance consists of using lower binder content, and therefore, lower Sodium concentrations. Using this technique obtains a better collapsing behavior and the ability of regenerating the used sand.

The polyester resin used to perform this investigation was an unsaturated orthophtalic polyester resin diluted in $44 \%$ styrene. The resin system is pre-accelerated by the manufacturer and the initiator used with this resin was methyl ethyl ketone peroxide MEKP (2\% in mass).

\section{Experimental Procedure and Results}

The formulation of the polymer concrete used $90 \%$ of foundry, recycled and fresh, sand and $10 \%$ of polyester resin, in mass. For each formulation, three cylindrical specimens were cast. All polymer concrete specimens were allowed to cure for 7 days at room temperature and then post-cured at $70{ }^{\circ} \mathrm{C}$ for 3 hours, before being tested in compression.

Polymer concrete specimens were compacted in a $\phi 50 \times 100 \mathrm{~mm}$ steel cylindrical mold, according to the RILEM standard PC- ${ }^{[15]}$. For each formulation 5 specimens were cast.

Cylinder polymer mortar specimens were tested in compression at the loading rate of $1.25 \mathrm{~mm} / \mathrm{min}$ according to the ASTM C39-93 standard $^{16}$. All specimens were instrumented with optical fibers as shown in Figures 1 and 2. Compressive strength and chord modulus of elasticity in compression were calculated according the following equation:

$$
\sigma_{c}=\frac{F}{A}
$$

where $\sigma_{c}$ is the compressive strength; $F$ is the maximum load recorded; and $\mathrm{A}$ is the cross-sectional area of cylinder specimens.

The optical system used in the experiment was composed of a broadband source, coupler and an optical spectrum analyzer (OSA) to monitor the position of the FBG sensor. The compressive loads applied to the polymer concrete specimen were transmitted to an embedded FBG sensor and the wavelength variations were taken with OSA. Figure 3 shows the scheme of the setup used.

Figure 4 shows the experimental results of compression test monitoring using FBG sensors embedded in polymer concrete taken under the consideration of equation 1 and constant temperature. The results indicated a good agreement predicate, i.e., the compressive strain increases with increasing the applied load. The maximum compressive stress for fresh polymer concrete is $6.84 \mathrm{MPa}$ associated to compressive strain of $194.3 \mu \varepsilon$, at this point the specimen starts to damage. The figure clearly depicts the decreasing of the stress and strain.

In average, recycled polyester polymer concrete compressive strength is $97.8 \%$ higher than fresh sand polyester polymer concrete. The fresh sand PC shows consistent results with low standard devia-

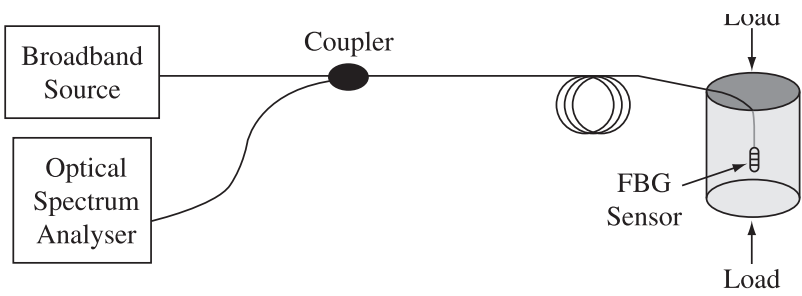

Figure 3. Experimental Set-up. 


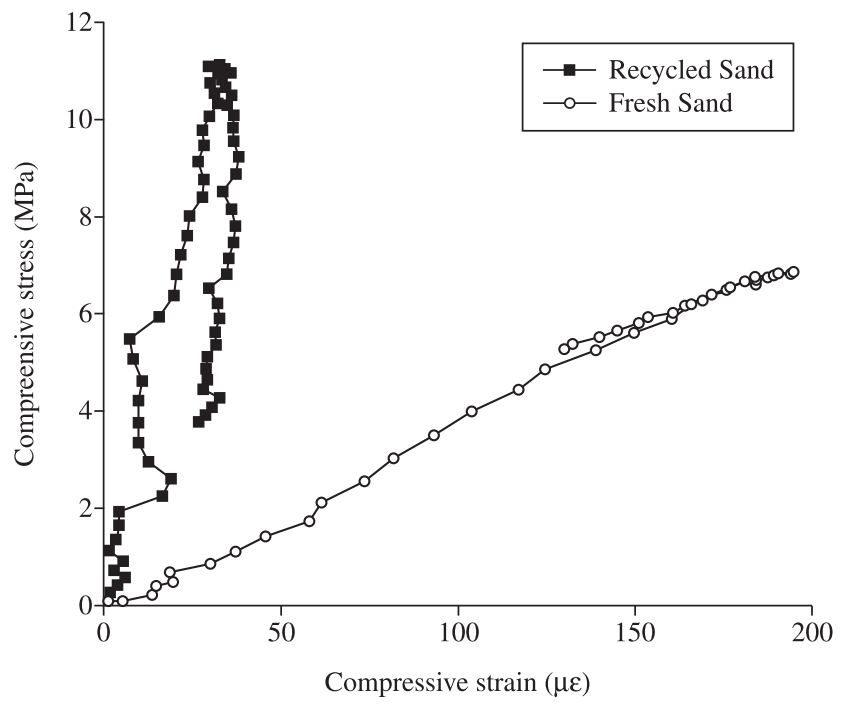

Figure 4. Compression test monitoring using FBG sensors embedded in polymer concrete.

Table 1. Polyester Fresh and Recycled Test Results.

\begin{tabular}{ccc}
\hline Specimens & Fresh & Recycled \\
\hline 1 & 5.53 & 7.48 \\
2 & 5.79 & 10.83 \\
3 & 5.88 & 17.81 \\
4 & 6.84 & 11.22 \\
5 & 6.36 & 12.82 \\
Average & 6.08 & 12.03 \\
St.Dev. & 0.52165 & 3.76931 \\
COV & 8.58261 & 31.32745 \\
C.I. 95\% & 0.54752 & 3.95630 \\
\hline
\end{tabular}

St.Dev. - Standard Deviation

COV - Covariance

C.I. $95 \%$ - Confidence Interval at $95 \%$

tion. The recycled PC also shows good convergence test results, except for the third specimen (Table 1).

\section{Conclusions}

Strain measurements in polymer concrete made with recycled and fresh sand structures by using fiber-optic Bragg grating (FBG) sensors were experimentally conducted.

In spite of the good results, the embedded process of the FBG sensor within polymer concrete must be improved and efforts will be made to develop a new mechanical transducer to overcome possible problems related to the fiber fragility ${ }^{14}$. Instable measurements were verified during tests due to possible temperature change during compressive deformation.

According to previous studies performed by researchers, the difference in the compressive strength is not the same that was recorded in this research ${ }^{17,18}$. Normally, the recycled and fresh sand produces similar results, but in previous studies the furanic resin had acid catalyst and this sand has Sodium-Silicate as a binder. This result indicates that the residue of foundry sand influences its performance as aggregate. Therefore the recycled sand component proves to be an important factor to be analyzed.

\section{Acknowledgements}

We gratefully acknowledge the financial support of FAPERJ, under JOVEM CIENTISTA DO ESTADO scholarship and CNPQ.

\section{References}

1. Fowler DW. Polymers in concrete: a vision for the 21 st century. Cement Concrete Composites.1999; 21(5-6):449-452.

2. Ohama Y. Recent Progress in Concrete-Polymer Composites, Review Article. Advanced Cement Based Materials. 1997; 5(1):31-40.

3. Fowler DW. Polymers in Concrete: Where have we been and where are we going? In: Proceedings of 10th International Conference on Polymers in Concrete; Hawaii; 2001. Paper 82.

4. Czarnecki L. Polymers in concrete on the edge of the millennium. In: Proceedings of 10th International Conference on Polymers in Concrete; Hawaii; 2001. Paper 93.

5. Letsh R. Polymer concrete properties and structural applications. In Proceedings of International Conference on Polymer Concretes, Mortars and Asphalts; Oporto; 2002. p.31-43.

6. Takashima S, Asanuma $\mathrm{H}$ and Niitsuma H. A Water Flowmeter Using Dual Fiber Bragg Grating Sensors and Cross-correlation Technique. Sensors and Actuators A. 2004; 116(1):66-74.

7. Yeo TL. Characterization of a polymer-coated fibre Bragg grating sensor for relative humidity sensing. Sensors and Actuators B. 2005; 110(1):148-155

8. Othonos A and Kalli K. Fiber Bragg Grating - Fundamentals and Applications in Telecommunications and Sensing. Norwood, MA: Artech House, Inc.; 1999.

9. Guemes JA and Menéndez JM. Response of Bragg grating fiber-optic sensors when embedded in composite laminates. Composite Science and Technology. 2002; 62(7-8):959-966.

10. Kuang KSC, Kenny R, Whelan MP, Cantwell WJ and Chalker PR. Embedded fibre Bragg grating sensors in advanced composite materials. Composite Science and Technology. 2001; 61(10):1379-1387.

11. Takeda N, Yashiro S and Okabe T. Estimation of the damage patterns in notched laminates with embedded FBG sensors. Composites Science and Technology. 2006; 66(5):684-693.

12. Colpo F, Humbert L, Giaccari P and Botsis J. Characterization of residual strains in an epoxy block using an embedded FBG sensor and the OLCR technique. Composites: Part A. 2006; 37(4):652-661.

13. Nunes LCS, Valente LCG and Braga AMB. Analysis of a Demodulation System for Fiber Bragg Grating Sensors Using Two Fixed Filters. Optics and Lasers Engineering. 2004; 42(5):529-542.

14. Leng JS, Barnes RA, Hameed A, Winter D, Tetlow J, Mays GC and Fernando GF. Structural NDE of concrete structures using protected EFPI and FBG sensors. Sensors and Actuators A. 2006; 126(2):340-347

15. RILEM. $P C-2$ : Method of making polymer concrete and mortar specimens. Technical Committee TC-113 Test Methods for ConcretePolymer Composites (CPT). France: International Union of Testing and Research Laboratories for Materials and Structures; 1995.

16. ASTM C39 / C39M - 05e1: Standard Test Method for Compressive Strength of Cylindrical Concrete Specimens. USA: ASTM; 2005.

17. Sousa LM, Reis JML and Ferreira AJM. Characterization of Polymer Concrete made with Recycled Aggregate. In Proceedings of the 11th European Conference on Composite Materials; Rhodes; 2004.

18. Sousa LM, Reis JML and Ferreira AJM. Fracture Mechanics of Polymer Concrete made with Recycled Aggregate. In Proceedings of the 9th Portuguese Conference on Fracture; Setúbal; 2004. 